\title{
Pemetaan partisipatif potensi jasa lanskap kawasan hutan Desa Pattaneteang, Kabupaten Bantaeng
}

\section{Participatory mapping of the potential landscape services of forest village area in Pattaneteang, Bantaeng Regency}

\author{
Firnawati $^{\mathrm{a}}$, Regan Leonardus Kaswanto ${ }^{\mathrm{b}}$, Sofyan Sjaf ${ }^{\mathrm{c}}$

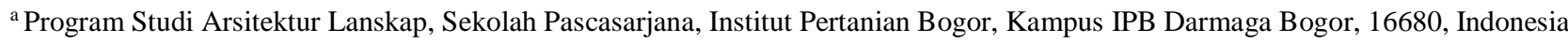 \\ [+62 85145266334] \\ ${ }^{\mathrm{b}}$ Divisi Manajemen Lanskap, Departemen Arsitektur Lanskap, Fakultas Pertanian, Institut Pertanian Bogor, Kampus IPB Darmaga \\ Bogor, 16680, Indonesia [+62 8121939739] \\ 'Departemen Sains Komunikasi dan Pengembangan Masyarakat, Fakultas Ekologi Manusia, Institut Pertanian Bogor, Kampus IPB \\ Darmaga Bogor, 16680, Indonesia [+62 81354510629]
}

\section{Article Info:}

Received: 11 - 12 - 2020

Accepted: 16 - 04 - 2021

Keywords:

Landscape services, participatory mapping, sustainability, village forest

\section{Corresponding Author:}

Kaswanto

Divisi Manajemen Lanskap,

Departemen Arsitektur Lanskap,

Fakultas Pertanian,

Institut Pertanian Bogor;

Tel. +62812193979

Email:

kaswanto@apps.ipb.ac.id

\begin{abstract}
Forests are a source of landscape services that are important for the sustainability of ecosystems. The Ministry of Forestry has provided access to village communities to manage forest areas legally through a village forest scheme with management access rights for 35 years. Participatory mapping is a type of public participation that includes the creation and/or use of spatial information for various purposes. Spatial data allows the identification of relationships between landscape services and their characteristics and also administrative units. This study aims to identify the potential characteristics and services of the Pattaneteang Village Forest. The method used is a spatial analysis carried out on land use maps based on drone images in Pattaneteang Village and qualitative methods in structured interviews, questionnaires, and focus group discussions. The results showed the quality of landscape services for biodiversity, and stored carbon in the Village of Pattaneteang is in the "very good" level, having a high-value economic role with a total score of 9 in Utilization Village Forest. The total score of cultural roles from the Pattanateang Village Forest is 4 for the Disputed Village Forest and the Utilization Village Forest, which means it has low cultural value, and a score of 5 for the Core Village Forest area means moderate cultural value.
\end{abstract}

How to cite (CSE Style $8^{\text {th }}$ Edition):

Firnawati, Kaswanto RL, Sjaf S. 2021. Pemetaan partisipatif potensi jasa lanskap kawasan hutan Desa Pattaneteang, Kabupaten Bantaeng, Bogor. JPSL 11(2): 189-203. http://dx.doi.org/10.29244/jpsl.11.2.189-203.

\section{PENDAHULUAN}

Sumber penghidupan masyarakat pedesaan pada umumnya berbasis lanskap pertanian dan berkaitan erat dengan pemanfaatan sumber daya alam (SDA) dan jasa lanskap, termasuk yang berasal dari hutan. Jasa ekosistem, atau sering juga disebut sebagai jasa lanskap (landscape services), adalah jasa yang disediakan oleh proses dan fungsi ekosistem, yang dapat mencakup empat jenis jasa: penyediaan (provisioning), regulasi atau pengatur (regulating), pendukung (supporting) dan budaya (cultural) (MEA, 2005; Termorshuizen dan Opdam, 2009). Hutan merupakan salah satu sumber jasa lanskap yang penting bagi keberlanjutan ekosistem. Jasa lanskap dari hutan tersebut akan bermanfaat jika dikelola dengan baik. Pada wilayah Indonesia sendiri 
bentuk pengelolaan hutan telah diatur secara resmi di dalam aturan perundang-undangan. Berdasarkan konsep pengelolaan hutan yang lestari, Kementrian Kehutanan telah memberikan akses kepada masyarakat desa untuk mengelola kawasan hutan secara legal, salah satunya adalah skema hutan desa dengan hak akses pengelolaan selama 35 tahun. Pemerintah Sulawesi Selatan, dengan berdasarkan Surat Keputusan Menteri Kehutanan (sekarang Kementerian Lingkungan Hidup dan Kehutanan atau KLHK) Nomor 55/MANHUT-II/2010 telah menetapkan Hutan Desa di Kabupaten Bantaeng dengan luasan 704.0 ha terletak dalam wilayah administrasi Kecamatan Tompobulu, Kabupaten Bantaeng (Batari et al., 2017). Menurut Supratman dan Alif (2010) program pembangunan hutan desa Kabupaten Bantaeng merupakan salah satu bentuk devolusi pengelolaan hutan, yaitu pelimpahan kewenangan pemerintah kepada masyarakat desa untuk mengelola sumberdaya hutan.

Tahapan pertama pembangunan hutan desa ditandai dengan sejumlah aktivitas pelatihan, Focus Group Discusion (FGD), dan workshop yang bertujuan untuk meningkatkan pemahaman masyarakat atas hak, tanggung jawab, peran dan manfaat yang akan diperoleh para pihak dalam pengelolaan hutan desa. Tahap kedua ditandai dengan penyerahan Surat Keputusan Menteri Kehutanan tentang areal kerja hutan desa di Kabupaten Bantaeng kepada Bupati Bantaeng, serta penyerahan SK Gubernur Sulawesi Selatan tentang izin hak pengelolaan hutan desa kepada Badan Usaha Milik Desa (BUMDes) sebagai lembaga pengelola hutan desa. Tahap ketiga diawali dengan penyusunan dokumen perencanaan berupa Rencana Kerja Hutan Desa (RKHD) dan Rencana Tahunan Hutan Desa (RTHD) (Nurhaedah dan Hapsari, 2014). Menurut Supratman dan Sahide (2013) pembangunan hutan desa dapat memberi kontribusi untuk pengembangan keamanan mata pencaharian bagi masyarakat yang memiliki ketergantungan terhadap sumberdaya hutan, melalui tanggung jawab dan akuntabilitas yang lebih besar terhadap kebijakan dan institusi publik dalam penguasaan sumberdaya alam. Penyediaan jasa lanskap atau ekosistem sering dimodifikasi berdasarkan tipe penggunaan lahan, sistem produksi, dan intensitas penggunaan lahan. Jasa ekosistem didefinisikan oleh Millennium Ecosystem Assessment sebagai barang dan jasa yang disediakan oleh alam untuk memenuhi kebutuhan manusia yang esensial (MEA, 2005). Pengelolaan hutan yang efisien dan berkelanjutan untuk mengamankan penyediaan jasa lanskap dari waktu ke waktu sangat diperlukan (Delgado-Aguilar et al., 2017). Mekanisme Hutan Desa sebagai salah satu bagian dari bentuk pengeloaan hutan secara bersama telah memberikan dampak positif pada berbagai penyediaan jasa lanskap yang bermanfaat bagi masyarakat lokal, regional, nasional dan internasional (Kaswanto et al., 2016; Wood et al., 2019).

Pemetaan partisipatif adalah jenis partisipasi publik yang mencakup pembuatan dan/atau penggunaan informasi spasial untuk berbagai tujuan (Brown dan Kyttä, 2018). Pemetaan partisipatif merupakan upaya pemetaan oleh non-pakar dan/atau pemangku kepentingan (De Vreese et al., 2016). Diskusi partisipatif berkontribusi penting dalam pengetahuan sosial dan pembelajaran tentang model pengelolaan hutan (Marques et al., 2020). Data spasial memungkinkan identifikasi hubungan antara jasa lanskap dan karakteristik lanskap (misalnya tata guna dan/atau tutupan lahan) serta unit administratifnya (Delgado-Aguilar et al., 2019). Pelibatan masyarakat dalam aktivitas pemetaan diharapkan sebagai sebuah pendekatan yang memberikan ruang keterbukaan dan kepastian yang dibutuhkan untuk membangun Indonesia dari desa. Drone Participatory Mapping (DPM) adalah pendekatan pengumpulan Data Desa Presisi Tinggi yang mempertimbangkan dimensi spasial, teknologi tinggi, digital, dan partisipasi. Penggunaan drone (Unmanned Aerial Vehicle-UAV) dengan pelibatan warga desa diperuntukkan menghasilkan citra resolusi tinggi untuk kepentingan data spasial yang selama ini belum dimiliki desa (Sjaf, 2019). Secara ekologi kawasan hutan desa memiliki fungsi yang saling mendukung satu sama lain. Namun dalam pengelolaannya desa belum memiliki program yang terarah dalam pengelolaan kawasan hutan desanya. Hal inilah yang mendasari tujuan dari pelaksanaan penelitian ini yaitu untuk mengidentifikasi karakteristik dan potensi jasa lanskap kawasan hutan desa Kabupaten Bantaeng.

Pengamatan awal untuk menilai potensi jasa lanskap dilakukan pada peta orthophoto, peta penggunaan lahan dan pengamatan di lapangan. Berdasarkan peta penggunaan lahan lanskap Desa Pattaneteang dikelompokkan menjadi tiga bagian utama, yaitu kebun campuran, perkebunan cengkeh dan kopi, serta hutan desa. Terdapat beberapa jasa lanskap yang dijadikan fokus kajian pada penelitian ini yaitu, keanekaragaman hayati, kandungan karbon tersimpan, peran hutan terhadap perekonomian masyarakat dan peran hutan terhadap 190 
budaya lokal. Keempat penilaian jasa lanskap tersebut dijadikan fokus kajian karena pada saat ini menjadi isu penting dalam permasalahan pengelolaan lingkungan khususnya kawasan hutan desa dan peran penting keberadaan hutan. Pemetaan jasa lanskap dapat digunakan sebagai alat pendukung dalam pengambilan keputusan bagi perencana dan pemuat kebijakan dengan mempertimbangkan faktor-faktor yang mendasari ekologi maupun sosial (Kaswanto, 2017). Pemetaan jasa lanskap memberikan gambaran secara komprehensif tentang kondisi ekologi maupun permintaan dan kebutuhan masyarakat setempat (Baró et al., 2016). Pemetaan partisipatif terhadap potensi jasa lanskap adalah cara untuk menyusun berbagai nilai lanskap yang memberi representasi visual untuk menginformasikan perencanaan konservasi lanskap (Bösch et al., 2018).

\section{METODE}

\section{Lokasi dan Waktu Penelitian}

Penelitian ini dilaksanakan di Desa Pattaneteang, Kecamatan Tompobulu, Kabupaten Bantaeng, Provinsi Sulawesi Selatan (Gambar 1). Secara geografis, Desa Pattaneteang terlatak antara 119057'53' dan 12002'9', Bujur Timur (BT) dan 5022'31" dan 5024'40" Lintang Selatan (LS). Secara administratif Desa Pattaneteang memiliki luas desa mencapai 1309.9 ha dengan hutan desa seluas 339.0 ha. Waktu penelitian dimulai pada Bulan Oktober 2019 hingga Mei 2020. Pemilihan Desa Pattanateang sebagai lokasi penelitian karena desa ini mulai menggiatkan pemetaan partisipatif dan kawasan hutan desa yang dimiliki adalah bagian langsung dari Kawasan Hutan Lindung Gunung Bawakaraeng-Lompobattang.

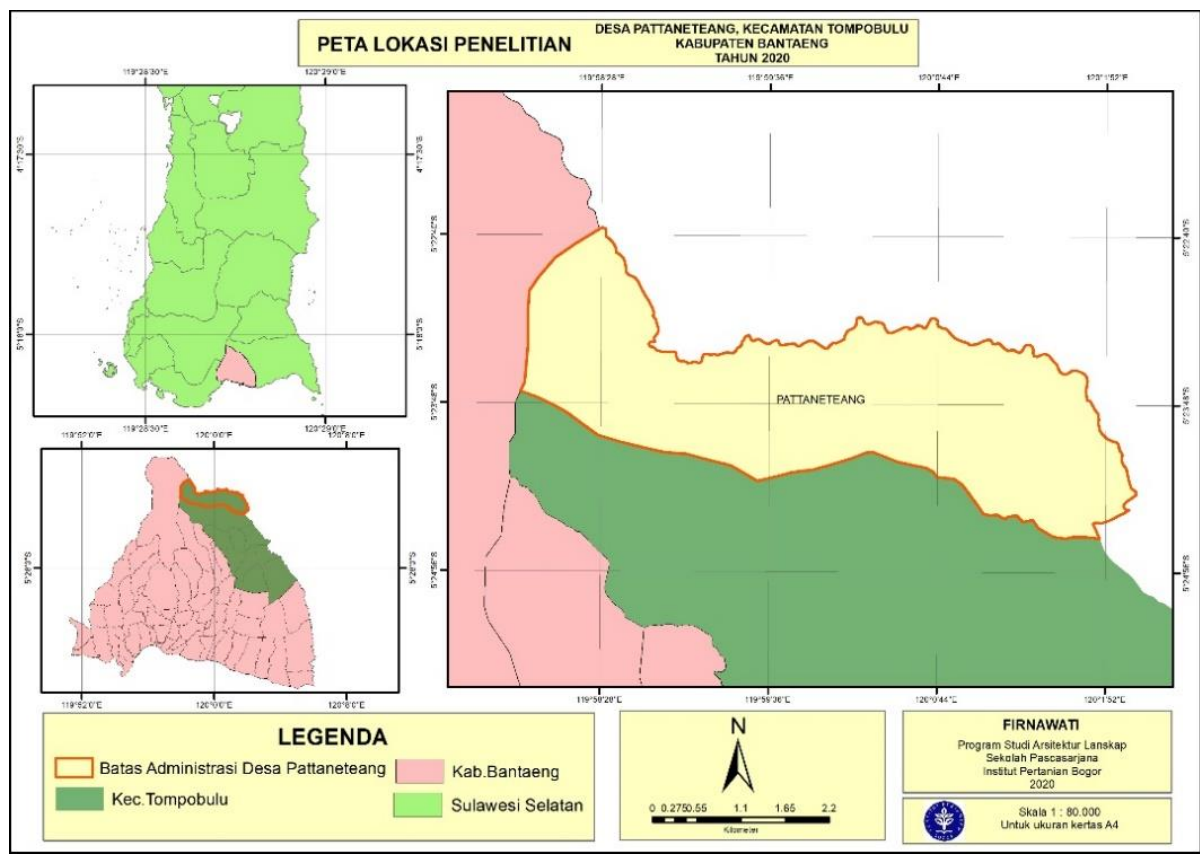

Gambar 1 Lokasi penelitian

\section{Metode Pengumpulan Data}

Metode yang digunakan dalam penelitian ini adalah metode analisis spasial dan metode kualitatif yang digunakan sebagai upaya untuk memperoleh informasi terkait objek penelitian yang dapat memberikan jawaban yang relevan bagi pertanyaan dalam rumusan penelitian. Metode pengumpulan data dilakukan melalui studi pustaka dan studi lapangan. Studi pustaka dilakukan dengan mengkaji sumber tertulis dari berbagai sumber referensi baik primer maupun sekunder, sedangkan studi lapang dikumpulkan dengan cara berinteraksi langsung dengan situasi lanskap secara langsung, yaitu dengan mengamati, mengidentifikasi, wawancara terstruktur, kuesioner, dan pertemuan melalui diskusi kelompok terarah (Focus Group Discussion - FGD). 


\section{Metode Analisis Data}

Analisis potensi jasa lanskap melalui analisis spasial yang dilakukan pada peta penggunaan lahan berdasarkan citra drone di Desa Pattaneteang. Selanjutnya adalah mengintegrasikan peta penggunaan lahan tersebut dengan nilai jasa lanskap. Penilaian potensi jasa lanskap dilakukan melalui metode scoring. Pemberian nilai/skor jasa lanskap pada jasa keanekaragaman hayati dan kandungan karbon tersimpan dilakukan dengan merujuk pada berbagai literatur hasil penilaian jasa lanskap suatu kawasan yang tersaji pada Tabel 1 dan Tabel 2. Penilaian jasa lanskap pada penelitian ini dilakukan berdasarkan beberapa studi literatur dan juga subjektivitas peneliti.

Tabel 1 Penilaian jasa lanskap terhadap keanekaragaman hayati berdasarkan tipe penutupan lahan

\begin{tabular}{clc}
\hline No & Tipe Penutup Lahan & Nilai* \\
\hline 1 & Hutan Primer (inti) & 8 \\
2 & Kebun Campuran & 7 \\
3 & Hutan Sekunder (Pemanfaatan) & 6 \\
4 & Kebun Kopi & 5 \\
5 & Tegalan/belukar & 4 \\
6 & Kebun Cengkeh & 3 \\
7 & Sawah & 2 \\
8 & Lahan Terbangun & 1 \\
\hline
\end{tabular}

Sumber: Hendrawan et al. (2015), Siarudin et al. (2017), Rahayu et al. (2017), Swastikaningrum et al. (2012) *dengan modifikasi

Tabel 2 Penilaian jasa lanskap terhadap karbon tersimpan berdasarkan tipe penutupan lahan

\begin{tabular}{|c|c|c|}
\hline No & Tipe Penutup Lahan & Nilai* \\
\hline 1 & Hutan Primer (inti) & 8 \\
\hline 2 & Hutan Sekunder (Pemanfaatan) & 7 \\
\hline 3 & Kebun Campuran & 6 \\
\hline 4 & Kebun Kopi & 5 \\
\hline 5 & Kebun Cengkeh & 4 \\
\hline 6 & Tegalan/belukar & 3 \\
\hline 7 & Sawah & 2 \\
\hline 8 & Lahan Terbangun & 1 \\
\hline
\end{tabular}

Sumber: Sularso et al. (2011), Manuri et al. (2011), Wijaya et al. (2017), Hairiah et al. (2011) *dengan modifikasi

Setelah dilakukan scoring selanjutnya menentukan tinggi rendahnya nilai jasa lanskap berdasarkan luas kawasan. Nilai jasa lanskap dihitung dengan melakukan perkalian antara luas masing-masing tutupan lahan dengan tipe masing-masing jasa lanskap kemudian dibagi dengan total luas kawasan, sehingga didapatkan ratarata nilai jasa lanskap dengan skala sebagaimana yang disajikan pada Tabel 3.

Selanjutnya penilaian peran ekonomi hutan desa berdasarkan toolkit hasil konsorsium HCVN (2008). Penilaian peran hutan terhadap perekonomian masyarakat setempat dilakukan dengan pemberian skor pada tiap hutan berdasarkan kriteria penilaian kepentingan pada Tabel 4. Kriteria penilaian mencakup pemanfaatan, peran dan dampak keberadaan hutan desa tersebut. Skor total kurang dari 5 dikategorikan bernilai ekonomi rendah, skor antara 5 sampai 7 dikategorikan bernilai ekonomi sedang, dan skor lebih dari 7 dikategorikan bernilai ekonomi tinggi. Kemudian, hasil penilaian dipetakan ke dalam peta peran ekonomi hutan. 
Tabel 3 Interpretasi nilai jasa lanskap

\begin{tabular}{cc}
\hline Nilai Jasa Lanskap & Interpretasi \\
\hline $0.00-1.00$ & Sangat tidak baik \\
$1.01-2.00$ & Tidak baik \\
$2.01-3.00$ & Kurang baik \\
$3.01-4.00$ & Cukup baik \\
$4.01-5.00$ & Baik \\
$5.01-6.00$ & Sangat baik \\
$6.01-7.00$ & Sangat baik sekali \\
\hline
\end{tabular}

Sumber: Rohmah (2014)

Tabel 4 Kriteria penilaian kepentingan hasil hutan bagi perekonomian masyarakat

\begin{tabular}{llll}
\hline \multirow{2}{*}{ Indikator } & \multicolumn{1}{c}{ 1 (rendah) } & \multicolumn{1}{c}{ Skor (sedang) } & \multicolumn{1}{c}{3 (tinggi) } \\
\cline { 2 - 4 } $\begin{array}{lll}\text { Frekuensi masyarakat } \\
\text { dalam memanfaatkan } \\
\text { hutan }\end{array}$ & $\begin{array}{l}\text { Sementara dan } \\
\text { sewaktu-waktu (hanya } \\
\text { pada masa sulit) }\end{array}$ & $\begin{array}{l}\text { Periodik (hanya pada } \\
\text { musim tertentu) }\end{array}$ & $\begin{array}{l}\text { Sepanjang tahun } \\
\text { (aktifitas sehari-hari) }\end{array}$ \\
\hline Peranan hutan bagi & Menurun (karena & Dibatasi risiko & Fundamental (untuk \\
kehidupan & kurang & (subsisten pada masa & memenuhi kebutuhan \\
& menguntungkan) & sulit) & sehari-hari) \\
\hline Dampak jika akses & Minimal (sudah & Transisional (sulit & $\begin{array}{l}\text { Kritis dan sulit } \\
\text { terhadap hutan }\end{array}$ \\
tersedia alternatif & namun kebutuhan dapat & (berpengaruh secara \\
dikurangi & sumber yang lebih & digantikan sumber daya & permanen maupun \\
& baik) & lain) & temporal) \\
\hline
\end{tabular}

Sumber: Byron dan Arnold (1999) dengan modifikasi

Tabel 5 Kriteria penilaian kepentingan hutan terhadap pemenuhan kebutuhan budaya

\begin{tabular}{|c|c|c|c|}
\hline \multirow{2}{*}{ Indikator } & \multicolumn{3}{|c|}{ Skor } \\
\hline & 1 (rendah) & 2 (sedang) & 3 (tinggi) \\
\hline $\begin{array}{l}\text { Zonasi kawasan sakral } \\
\text { atau situs arkeologi } \\
\text { terkait budaya lokal }\end{array}$ & Tidak ada & $\begin{array}{l}\text { Memiliki satu } \\
\text { kawasan/situs }\end{array}$ & $\begin{array}{l}\text { Memiliki beberapa } \\
\text { kawasan/situs }(>1)\end{array}$ \\
\hline $\begin{array}{l}\text { Spesies tumbuhan/hewan } \\
\text { yang bernilai bagi budaya } \\
\text { lokal }\end{array}$ & $\begin{array}{l}\text { Tidak memiliki spesies } \\
\text { yang bernilai budaya }\end{array}$ & $\begin{array}{l}\text { Memiliki spesies yang } \\
\text { bernilai budaya namun } \\
\text { tidak menjadi sumber } \\
\text { utama pemenuhan } \\
\text { kebutuhan budaya }\end{array}$ & $\begin{array}{l}\text { Memiliki spesies } \\
\text { bernilai budaya dan } \\
\text { menjadi sumber utama } \\
\text { pemenuhan kebutuhan } \\
\text { budaya }\end{array}$ \\
\hline $\begin{array}{l}\text { Lokasi upacara adat atau } \\
\text { aktivitas ritual }\end{array}$ & $\begin{array}{l}\text { Tidak pernah menjadi } \\
\text { lokasi ritual }\end{array}$ & $\begin{array}{l}\text { Pernah menjadi lokasi } \\
\text { upacara adat namun } \\
\text { tidak sering }\end{array}$ & $\begin{array}{l}\text { Pernah dan sering } \\
\text { menjadi lokasi upacara } \\
\text { adat }\end{array}$ \\
\hline
\end{tabular}

Sumber: HCVN (2008) dengan modifikasi

Penilaian kepentingan hutan terhadap budaya lokal dilakukan dengan pemberian skor pada tiap hutan berdasarkan tiga indikator terkait dengan zonasi kawasan sakral, nilai spesies dari perspektif budaya, dan aktivitas ritual. Indikator dan kriteria penilaian kepentingan disajikan pada Tabel 5. Skor total yang kurang dari 5 dikategorikan sebagai hutan bernilai budaya rendah, skor 5 sampai 7 dikategorikan hutan bernilai budaya 
sedang, dan skor lebih dari 7 dikategorikan sebagai hutan bernilai budaya tinggi. Selanjutnya, hasil penilaian tersebut kemudian dituangkan ke dalam peta peran budaya hutan.

\section{HASIL DAN PEMBAHASAN}

Penggunaan lahan utama di Desa Pattaneteang meliputi Hutan Desa, perkebunan cengkeh dan kopi, kebun campuran dan pemukiman. Selain itu juga berupa sawah, tegalan/semak belukar dan kawasan Pembangkit Listrik Tenaga Mini Hidro (PLTMH). Berdasarkan hasil Drone Participatory Mapping (DPM) dihasilkan peta penggunaan lahan dengan luas masing-masing penggunaan lahan disajikan pada Tabel 6.

Tabel 6 Luas penggunaan lahan Desa Pattaneteang, Kecamatan Tompobulu, Kabupaten Bantaeng

\begin{tabular}{clcc}
\hline No & \multicolumn{1}{c}{ Penggunaan Lahan } & Luas (ha) & Persentase \% \\
\hline 1 & PLTMH & 7.67 & 0.7 \\
2 & Pemukiman & 21.95 & 2.0 \\
3 & Sawah & 18.69 & 1.7 \\
4 & Tegalan/belukar & 50.29 & 4.5 \\
5 & Kebun Kopi & 127.19 & 11.5 \\
6 & Kebun Campuran & 163.99 & 14.8 \\
7 & Kebun Cengkeh & 291.43 & 26.3 \\
8 & Hutan Desa & 428.71 & 38.6 \\
\hline Total & & 1109.92 & 100.00 \\
\hline
\end{tabular}

Kondisi tutupan lahan di Desa Pattaneteang didominasi oleh hutan desa dengan luas 428.71 ha (38.6\%). Kawasan hutan desa tersebut oleh pemerintah desa dikelompokkan dalam tiga jenis hutan berdasarkan status pemanfaatannya, yaitu Hutan Desa Pemanfaatan, Hutan Desa Inti dan Hutan Desa Sengketa.

\section{Keanekaragaman Hayati}

Tanaman yang dominan di Desa Pattaneteang adalah tanaman komoditas perkebunan. Cengkeh (Syzigium aromaticum) dan kopi (Coffea robusta dan Coffea arabica) adalah tanaman komoditas utama yang mendominasi kebun-kebun warga. Secara keseluruhan total luasan untuk budidaya cengkeh dan kopi baik itu monokultur maupun agroforestri adalah 617.51 ha. Pada skala lanskap, ekosistem dengan keanekaragaman hayati yang tinggi, berfungsi sebagai penyedia jasa lanskap seperti regenerasi benih, perlindungan habitat satwa dan tumbuhan, pengaturan iklim dan hidrologi. Lanskap yang berkelanjutan idealnya tidak hanya memberi manfaat ekonomi tetapi juga berperan sebagai penyedia jasa lanskap (Rahayu et al., 2017).

Berdasarkan hasil penilaian, nilai rata-rata potensi jasa lanskap keanekeragaman hayati di Desa Pattaneteang adalah 5.38 (Tabel 7). Nilai tersebut menunjukkan kualitas jasa lanskap keanekaragaman hayati di Desa Pattaneteang berada dalam tingkatan "sangat baik". Peta nilai potensi jasa keanekaragaman hayati di Desa Pattaneteang dapat dilihat pada Gambar 2. Berdasarkan hasil penilaian, jasa keanekaragaman hayati Desa Pattaneteang memiliki potensi terbesar pada kawasan hutan primer (hutan inti). Di samping memiliki luas terbesar di Desa Pattaneteang, kawasan hutan primer tersebut adalah kawasan berstatus hutan lindung yang masih tetap lestari dengan beragam jenis tumbuhan dan hewan yang hidup di dalamnya.

Perbedaan nilai keanekaragaman dapat dipengaruhi oleh perbedaan pola pengelolaan tutupan lahan. Lahan pertanian dengan jenis tanaman pangan, perkebunan monokultur dan hortikultura dikelola lebih intensif dibandingkan kebun campuran maupun hutan alami yang lebih sedikit menerima intervensi manusia (Saputra dan Wiryani, 2013). Lahan intensif merupakan areal yang secara terus-menerus digunakan oleh masyarakat untuk penggunaan lahan tertentu, seperti bertani dan berkebun. Pada tutupan lahan pertanian dan perkebunan, petani melakukan pemilihan dan pengaturan jenis tanaman, melakukan pembersihan dan mengontrol jenis tumbuhan yang diinginkan maupun tidak diinginkan (gulma) yang tumbuh di sekitar tanaman utama. 
Keanekeragaman hayati pada hutan alami lebih tinggi khususnya dalam hal jumlah spesies kayu, dan tegakan di bawahnya. Selain itu, kemerataan dan kekayaan spesies lebih besar, sedangkan pada daerah hutan pemanfaatan dan perkebunan kopi telah terjadi penurunan keanekaragaman hayati akibat bentuk pengelolaan yang cenderung bersifat monokultur (Wood et al., 2019).

Tabel 7 Penilaian jasa lanskap terhadap potensi nilai keanekaragaman hayati Desa Pattaneteang

\begin{tabular}{llcc}
\hline No & Tipe Penutup Lahan & Nilai & Nilai Jasa Lanskap KH \\
\hline 1 & Hutan Primer (inti) & 8 & 1838.56 \\
2 & Kebun Campuran & 7 & 1147.93 \\
3 & Hutan Sekunder (Pemanfaatan) & 6 & 1193.34 \\
4 & Kebun Kopi & 5 & 635.95 \\
5 & Tegalan/belukar & 4 & 201.16 \\
6 & Kebun Cengkeh & 3 & 874.29 \\
7 & Lahan Terbangun (pemukiman) & 2 & 59.24 \\
8 & Sawah & 1 & 18.69 \\
\hline Total & & & 5969.16 \\
Rata rata nilai jasa keanekaragaman hayati & & 5.38 (Sangat Baik) \\
\hline
\end{tabular}

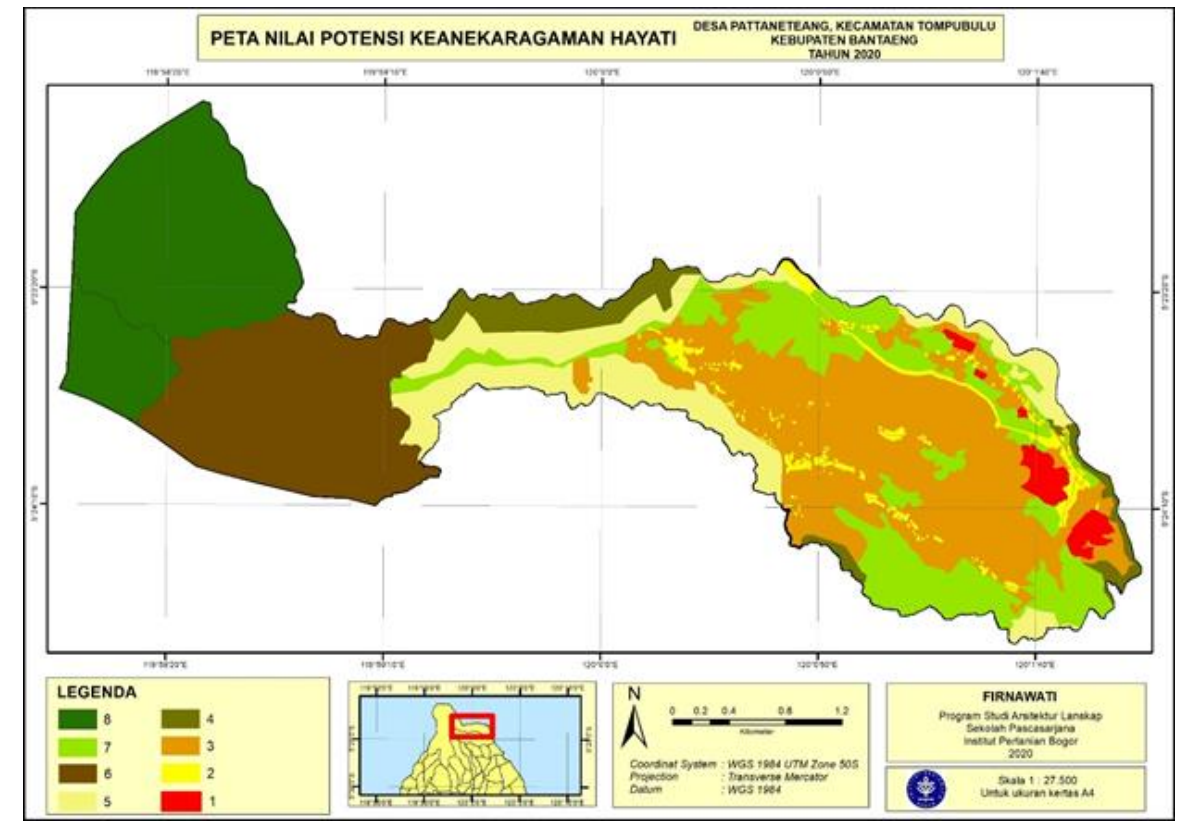

Gambar 2 Peta nilai jasa keanekaragaman hayati Desa Pattaneteang

Keanekaragaman hayati yang tinggi pada wilayah pedesaan memberikan manfaat yang besar bagi kehidupan masyarakat desa. Daerah dengan keanekaragaman tumbuhan yang tinggi akan memudahkan masyarakat pedesaan untuk memenuhi kebutuhan sehari-hari. Daerah dengan keanekaragaman hayati yang lebih tinggi menerima manfaat yang lebih besar dan beragam dari jasa lanskap yang berasal dari keragaman penggunaan lahan di sekitarnya (Zaehringer et al., 2017). Nilai keanekaragaman hayati sawah adalah yang terendah berdasarkan pola penggunaan lahan yang diterapkan Desa Pattaneteang, selain luasan yang kecil masyarakat juga memanfaatkan sawah bergantung pada curah hujan. Di samping itu sawah hanya dimanfaatkan untuk tujuan penanaman secara monokultur, yaitu padi. Interaksi antara tutupan tajuk dan musim adalah salah satu faktor yang memengaruhi kekayaan dan keanekaragaman hayati dalam suatu kawasan. Kelimpahan spesies yang habitatnya adalah hutan akan meningkat pada tutupan tajuk yang lebih besar (da Silva et al., 2019). 


\section{Karbon Tersimpan}

Berdasarkan hasil penilaian, nilai rata-rata potensi jasa lanskap cadangan karbon atau karbon tersimpan (C stock) di Desa Pattaneteang adalah 5.62 (Tabel 8). Nilai tersebut menunjukkan kualitas jasa lanskap karbon tersimpan di Desa Pattaneteang berada dalam tingkatan "sangat baik". Peta nilai potensi karbon tersimpan di Desa Pattaneteang dapat dilihat pada Gambar 3. Berdasarkan hasil penilaian, jasa karbon tersimpan Desa Pattaneteang memiliki potensi terbesar pada kawasan hutan primer (hutan inti). Hutan primer memiliki nilai potensi jasa lanskap karbon tersimpan terbesar karena selain memiliki luas lahan terbesar, jumlah tegakan, kerapatan dan diameter vegetasi hutan primer juga menjadi kriteria dalam menentukan penilaian, di samping itu terdapat beberapa jenis vegetasi dengan karbon tersimpan tinggi yang telah berusia puluhan tahun. Selain memiliki luas terbesar di Desa Pattaneteang, kawasan hutan primer tersebut adalah kawasan berstatus hutan lindung yang masih tetap lestari dengan beragam jenis tumbuhan dan hewan yang hidup di dalamnya.

\section{Tabel 8 Penilaian jasa lanskap terhadap potensi penyimpanan karbon tersimpan di Desa Pattaneteang}

\begin{tabular}{clcc}
\hline No & Tipe Penutup Lahan & Nilai & Nilai Jasa Lanskap C-Stock \\
\hline 1 & Hutan Primer (inti) & 8 & 1838.56 \\
2 & Hutan Sekunder (Pemanfaatan) & 7 & 1392.23 \\
3 & Kebun Campuran & 6 & 983.94 \\
4 & Kebun Kopi & 5 & 635.95 \\
5 & Kebun Cengkeh & 4 & 1165.72 \\
6 & Tegalan/belukar & 3 & 150.87 \\
7 & Sawah & 2 & 37.38 \\
8 & Lahan Terbangun (Pemukiman) & 1 & 29.62 \\
\hline & Total & 6234.27 \\
\multicolumn{2}{c}{ Rata-rata Nilai Jasa karbon Tersimpan } \\
\hline
\end{tabular}

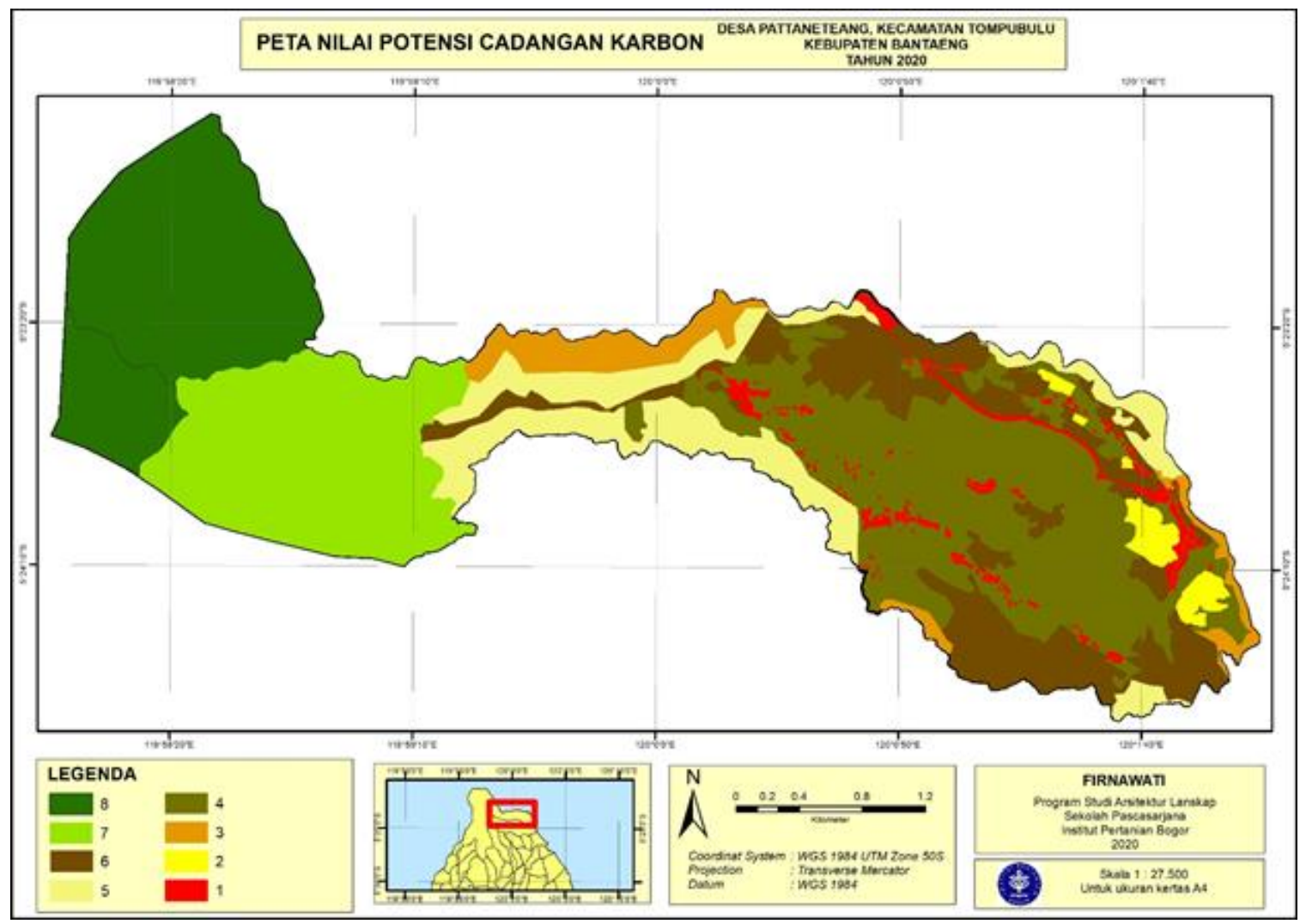

Gambar 3 Peta nilai kandungan karbon tersimpan Desa Pattaneteang 
Penyebaran karbon tersimpan pada kawasan hutan lindung lebih tinggi karena adanya pemberlakuan pembatasan terhadap eksploitasi hasil hutan, dibandingkan dengan hutan kemasyarakatan dan lahan pertanian yang dikelola masyarakat sebab memungkinkan adanya penebangan kayu maupun intervensi terhadap jenis dan jumlah tanaman yang diinginkan. Hutan tropis memainkan peran kunci dalam mitigasi perubahan iklim dengan menyerap dan menyimpan karbon dari atmosfer (Siraj, 2019). Salah satu strategi mitigasi perubahan iklim yang paling umum diusulkan adalah penyerapan karbon oleh vegetasi. Penyerapan karbon tersebut juga bergantung pada laju serapan karbon melalui fotosintesis dan laju pelepasan melalu repirasi, serta kestabilan penyimpanan karbon (Powell et al., 2018). Berkaitan dengan emisi karbon dioksida, hutan memiliki dua fungsi utama, pertama hutan berperan sebagai penyerap utama kabon dioksida di atmosfer dan yang kedua penggunaan energi dari sisa biomassa hutan akan mengurangi emisi tambahan $\mathrm{CO}_{2}$ dari pembakaran bahan bakar fosil (Gil et al., 2011). Ekstraksi dan penyimpanan karbon berlebih dari atmosfer ke dalam hutan dianggap sebagai salah satu mekanisme mitigasi perubahan iklim global (Anneli et al., 2007).

Mengurangi deforestasi dan degradasi adalah salah satu cara yang sangat penting untuk menurunkan emisi karbon global (Graham et al., 2020). Mencegah deforestasi artinya mengurangi jumlah emisi karbon sekaligus sebagai bentuk mitigasi perubahan iklim (Gurung et al., 2015). Deforestasi menyebabkan terjadinya penurunan jasa lingkungan pada hutan khususnya dalam penyimpanan karbon dan keanekaragman hayati (Zaehringer $e t$ al., 2017). Nilai karbon tersimpan penting untuk mengetahui kemampuan vegetasi dalam menyerap karbon dioksida maupun monoksida dalam suatu lanskap. Semakin besar jumlah karbon tersimpan yang dimiliki maka semakin besar jumlah emisi yang dapat diserap. Penyimpanan dan penyerapan karbon di suatu wilayah merupakan fungsi dari luasan lahan suatu kawasan dan persentase tutupan pohon atau total tutupan pohon terhadap kawasan tersebut (Nowak dan Crane, 2002).

\section{Peran Hutan terhadap Perekonomian Masyarakat}

Penilaian tingkat kepentingan atau peran keberadaan hutan terhadap kehidupan ekonomi masyarakat Desa Pattaneteang, kriteria yang digunakan meliputi partisipasi masyarakat dalam kegiatan pemanfaatan hutan, peran hutan dalam sistem kehidupan, dan dampak jika akses terhadap hutan dikurangi atau dibatasi (Gambar 4). Berdasarkan hasil wawancara mengenai partisipasi masyarakat dalam aktivitas pemanfaatan hasil hutan, mayoritas responden mengategorikan Hutan Desa Pemanfaatan sebagai kawasan yang bernilai tinggi bagi kehidupan perekonomian mereka, sedangkan untuk Hutan Desa Sengketa seluruh responden mengategorikan sebagai kawasan yang bernilai ekonomi rendah bagi kehidupan masyarakat Desa Pattaneteang.

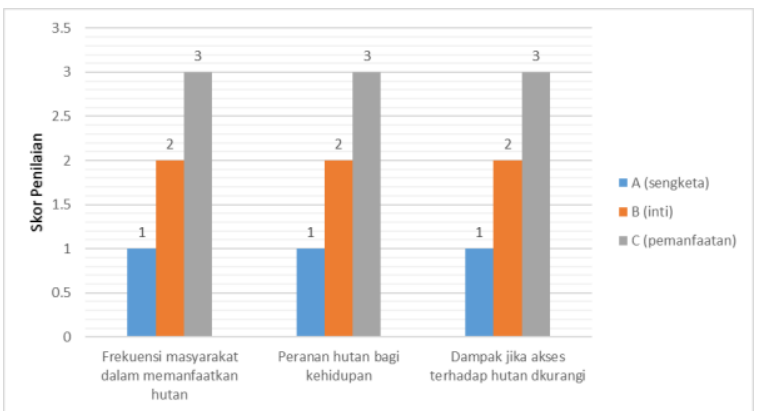

Gambar 4 Grafik nilai peran hutan desa bagi perekonomian masyarakat Desa Pattaneteang

Responden yang memberi nilai tinggi merupakan masyarakat yang memanfaatkan hutan sepanjang tahun sebagai aktivitas sehari-hari, sedangkan masyarakat yang memberi nilai sedang berarti masyarakat yang memanfaatkan hutan secara periodik atau hanya pada musim tertentu dan penilaian rendah adalah ketika frekuensi pemanfaatan hutan bersifat sementara atau sewaktu-waktu. Penilaian sedang sebagian besar adalah penilaian terhadap kawasan Hutan Desa Inti. Hutan Desa Inti merupakan kawasan yang juga ditetapkan sebagai kawasan hutan lindung, sehingga pemanfaatannya oleh masyarakat Desa Pattaneteang hanya pada musim 
tertentu (periodik). Oleh masyarakat Desa Pattaneteang Hutan Desa Inti dimanfaatkan untuk tujuan mencari madu hutan dan kayu bakar. Adapun responden yang memberi nilai rendah hanya memanfaatkan hutan sewaktu-waktu pada masa sulit atau tidak pernah ke hutan sama sekali. Frekuensi pemanfaatan hutan memberi gambaran umum bahwa masyarakat di Pattaneteang memiliki ketergantungan dengan hutan desa mereka, khususnya Hutan Desa Pemanfaatan.

Gambar 5 menunjukkan masyarakat Pattaneteang menilai peran Hutan Desa Sengketa bagi sistem kehidupan termasuk pada kategori rendah, selain karena status kawasan tersebut adalah hutan lindung, faktor lainnya adalah kawasan tersebut adalah Hutan Desa Sengketa yang jaraknya jauh dari permukiman masyarakat Desa Pattanateang, akses yang terbatas dan hasil yang kurang menguntungkan juga memengaruhi penilaian masyarakat terhadap kawasan hutan tersebut. Berbeda dengan Hutan Desa Pemanfaatan yang oleh masyarakat dinilai tinggi karena keberadaannya yang bersifat fundamental untuk memenuhi kebutuhan sehari-hari. Sebagian warga Desa Pattanaetang berprofesi sebagai petani kopi dan cengkeh yang lahannya adalah bagian dari kawasan hutan desa. Sehingga sumber penghasilan utama mereka berasal dari Hutan Desa Pamanfaatan. Sedangkan kawasan Hutan Desa Inti sendiri dinilai oleh masyarakat Desa Pattaneteteang sebagai kawasan yang bernilai sedang yaitu kawasan yang sifatnya dibatasi oleh risiko. Mengingat kawasan tersebut adalah kawasan yang berstatus hutan lindung sekaligus hutan penyangga Desa Pattaneteang. Penebangan pohon untuk tujuan kebutuhan rumah tangga diperbolehkan setelah memenuhi prosedur dan ketentuan yang ditetapkan oleh pemerintah setempat.

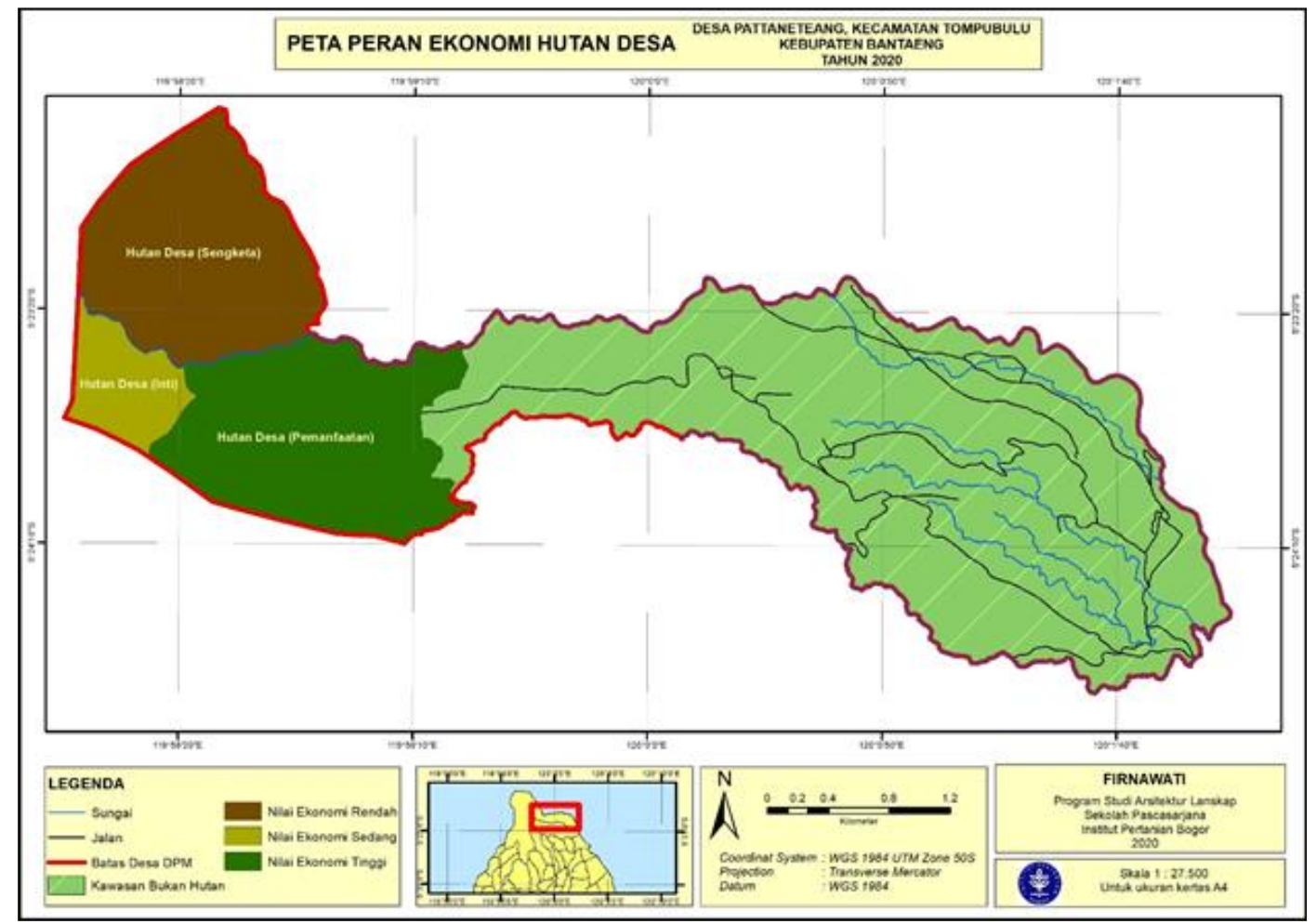

Gambar 5 Peta nilai peran Hutan Desa Pattaneteang secara ekonomi

Dampak yang ditimbulkan jika terjadi pengurangan akses terhadap hutan oleh masyarakat Desa Pattanateang masing-masing bernilai tinggi, sedang dan rendah. Hutan Desa Pemanfaatan adalah kawasan yang dianggap bernilai tinggi yaitu akan menyebabkan kritis dan sulit atau berpengaruh secara permanen maupun temporal terhadap perekonomian masyarakat, sedangkan Hutan Desa Inti dikategorikan bernilai sedang yaitu bersifat transisional atau menyulitkan namun tujuan pemenuhan kebutuhan dapat digantikan sumber daya lain, dan Hutan Desa Sengketa memiliki nilai rendah yaitu memberi dampak paling minimal sebab sudah tersedia alternatif sumber yang lebih baik. 
Secara umum masyarakat Desa Pattanetang menganggap Kawasan Hutan Desa Sengketa tersebut adalah bagian dari Kabupaten Bulukumba, akan tetapi berdasarkan ketetapan pemerintah kawasan tersebut masih termasuk dalam wilayah administratif Desa Pattaneteang, Kecamatan Tompobulu, Kabupaten Bantaeng. Pada dasarnya masyarakat Desa Pattaneteang bergantung pada hasil-hasil pertanian khususnya cengkeh dan kopi di kawasan Hutan Desa Pemanfaatan. Hal ini sesuai dengan (Rasmussen et al., 2017) yang menyebutkan bahwa hutan sebagai sumber mata pencaharian bagi sebagian besar masyarakat pedesaan, seperti, papan, makanan, pakan ternak, dan tanaman obat. Selain itu, manfaat lainnya berupa pendapatan tunai yang diperoleh dari penjualan hasil hutan serta manfaat ekologis yang secara tidak langsung memberikan kontribusi terhadap produktivitas pertanian.

Hutan di wilayah pedesaan dinilai sebagai barang ekonomi, faktor produksi sekaligus bagian dari lanskap. Sejauh ini, sebagian besar penilaian terhadap hutan sebagai barang ekonomi adalah hutan memberikan jasa penyediaan terutama produksi kayu. Sedangkan jasa ekosistem hutan lainnya tidak diperdagangkan di pasar. Secara keseluruhan manfaat jasa lingkungan tersebut jauh lebih besar jika dibandingkan dengan produksi kayu yang dinilai dengan harga pasar (Bösch et al., 2018).

Secara keseluruhan penilaian masyarakat terhadap peran ekonomi Hutan Desa Pattaneteang yaitu Hutan Desa Pemanfaatan bernilai tinggi, Hutan Desa Inti Bernilai Sedang dan Hutan desa Sengketa bernilai rendah. Meskipun kawasan hutan Desa inti juga adalah kawasan yang berstatus sebagai kawasan hutan lindung tetapi keberadaan hutan tersebut tidak memberikan dampak secara ekonomi bagi masyarakat Desa Pattaneteang. Manfaat ekonomi yang diberikan oleh hutan bagi masyarakat Desa Pattaneteang tentu dapat ditingkatkan melalui pemberdayaan dan penguatan lembaga. Hasil hutan bukan kayu seperti rotan dan madu adalah salah satu produk hasil hutan yang nilai jualnya dapat ditingkatkan. Sehingga bila dikembangkan, nilai ekonomi hutan menjadi lebih tinggi. Keberhasilan maupun kegagalan pengelolaan sumber daya hutan bersama tidak hanya bergantung pada kesehatan lembaga pengelola itu sendiri tetapi juga pada apakah pengelola dalam hal ini yaitu masyarakat juga mendapat dukungan dari pihak pemerintah setempat sebagai pembuat dan pelaksana kebijakan. Lebih khusus, keberhasilan atau kegagalan pengelolaan bersama bergantung pada mekanisme pengelolaan bersama apakah dapat memenuhi kebutuhan dan kepentingan masyarakat maupun pemerintah itu sendiri (Zhu et al., 2014)

\section{Peran Hutan Terhadap Budaya Masyarakat}

Peran hutan bagi aktivitas kebudayaan setempat di Desa Pattaneteang tidak melibatkan hutan. Di Desa Pattaneteang hutan hanya dijadikan sebagai kawasan yang menjadi sumber pendapatan oleh masyarakat dan penyedia jasa lingkungan lainnya. Hal ini berdasarkan hasil penilaian masyarakat yang menilai kawasan hutan sebagai kawasan yang bernilai budaya rendah maupun sedang berdasarkan tiga kriteria yang ditentukan (Gambar 6). Berdasarkan penilaian kriteria zonasi kawasan sakral atau situs arkeologi terkait budaya lokal, baik Hutan Desa Inti maupun Hutan Desa Pemanfaatan berada pada ketegori nilai budaya rendah. Hal ini karena di kawasan Hutan Desa Pattaneteang tidak memiliki zonasi kawasan yang disakralkan oleh masyarakat setempat maupun kawasan yang di dalamnya terdapat situs arkeologi.

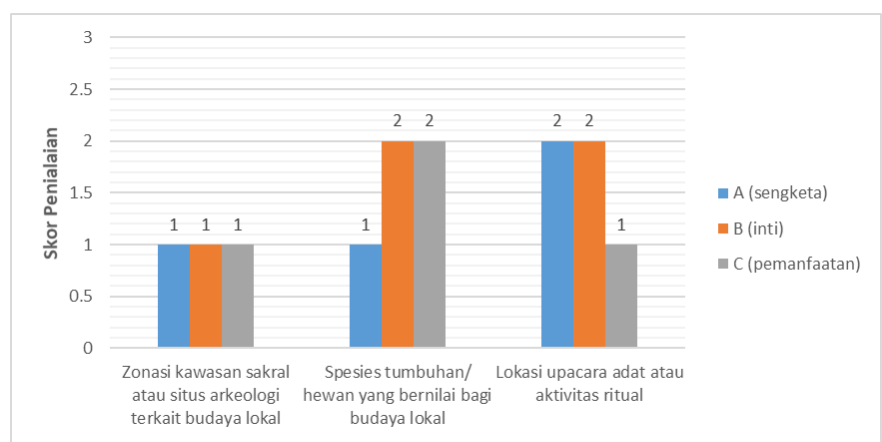

Gambar 6 Grafik nilai peran hutan desa bagi budaya lokal masyarakat Desa Pattaneteang 
Berdasarkan kriteria ada tidaknya spesies tumbuhan atau hewan yang bernilai bagi budaya lokal, peran Hutan Desa Inti dan Hutan Desa Pemanfaatan berada pada kategori sedang, sedangkan Hutan Desa Sengketa berada pada kategori rendah, penilaian rendah tersebut disebabkan oleh masyarakat Desa Pattaneteang yang tidak ikut memanfaatkan kawasan tersebut. Beberapa spesies tumbuhan yang bernilai budaya lokal bagi masyarakat Desa Pattaneteang adalah tanaman yang menjadi bagian dari prosesi pernikahan masyarakat Suku Makassar, seperti Inai (Lawsonia inermis) dan Nangka (Artocarpus heterophyllus) yang digunakan pada prosesi mappaccing yang berarti bersih atau suci untuk membersihkan jiwa dan raga calon pengantin, sebelum mengarungi bahtera rumah tangga. Selain itu juga terdapat jenis tanaman obat yang dimanfaatkan oleh masyarakat untuk tujuan pengobatan tradisional. Aktivitas upacara adat di kawasan hutan tak lagi dipraktikkan oleh masyarakat setempat. Akan tetapi beberapa masyarakat masih melakukan aktivitas ritual masing-masing meskipun saat ini sudah sangat jarang ditemui.

Sebagian besar aktivitas kebudayaan masyarakat Desa Pattaneteang tidak lagi melibatkan hutan. Situssitus yang bernilai budaya sebagaian besar terdapat di sekitar pemukiman maupun kebun masyarakat (Gambar 7). Tradisi yang masih dilakukan oleh masyarakat Desa Pattaneteang antara lain syukuran kelahiran, pernikahan, pannaung ri ere, pangadakkang ri nabitta, appalappasa', allapasa' jangang, pasalama, naik ri balla', dan saluttana. Beberapa ritual itu diadakan di Balla Lompoa yang merupakan sebuah rumah adat yang berada di dusun Balla Lompoa. Ritual juga dilakukan di beberapa tempat, seperti di (sumur) Buhung Tambarayya, Buhung Lompoa, Buhung Lompoa Borong Pattong, dan saukang yang ada di Dusun Biring Ere. Ritual yang mereka lakukan dinamakan pannaung ri ere, hingga saat ini ritual tersebut masih rutin dilaksanakan oleh masyarakat yang datang untuk melakukan ritual tersebut baik warga dalam desa maupun dari luar desa (Pemerintah Desa Pattaneteang, 2019).

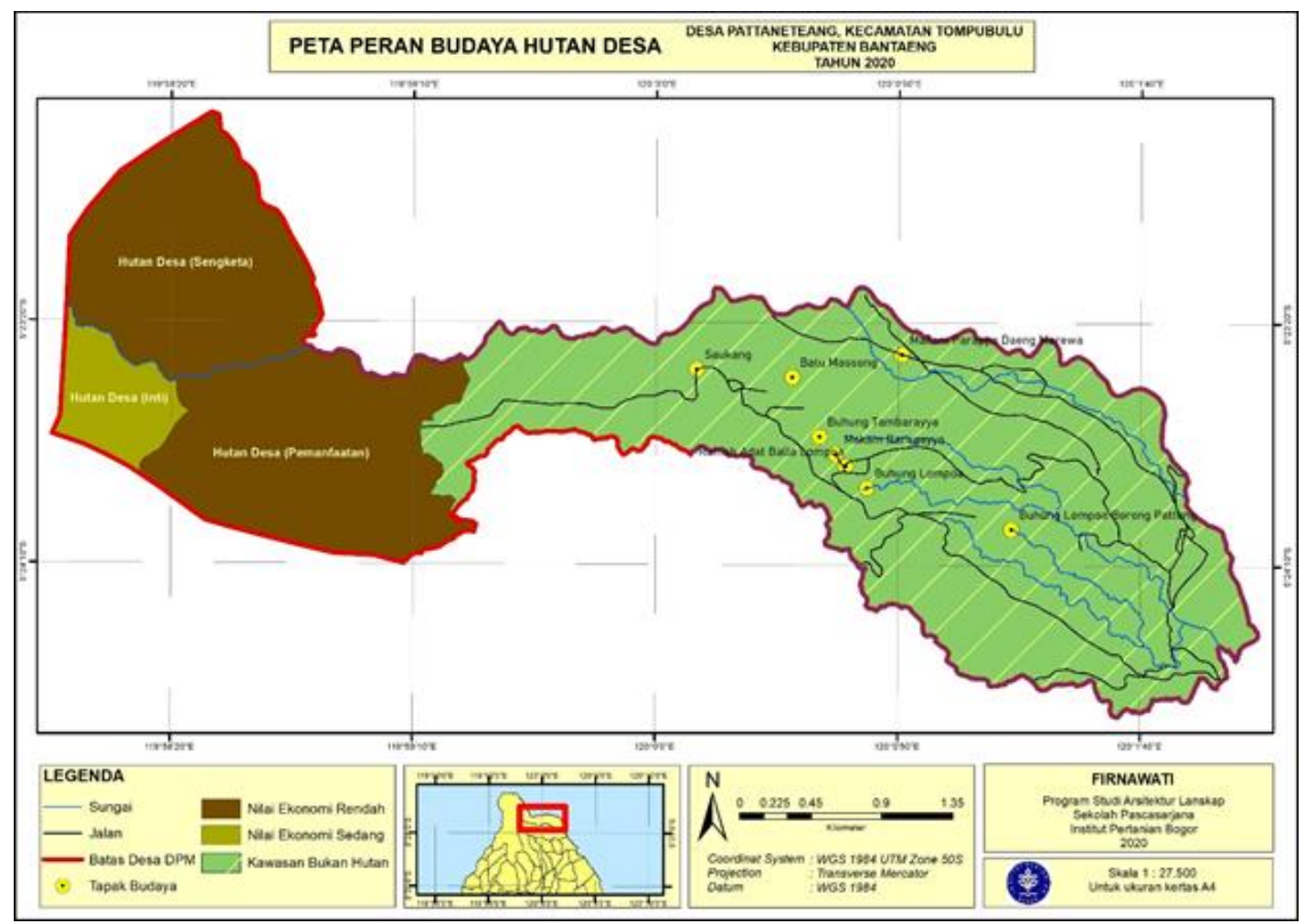

Gambar 7 Peta nilai peran Hutan Desa Pattaneteang bagi budaya lokal

Berdasarkan nilai total scoring penilaian masyarakat terhadap peran budaya Hutan Desa Pattaneteang yaitu Hutan Desa Pemanfaatan dan Hutan Desa Inti bernilai sedang, sementara Hutan Desa Sengketa bernilai rendah. Situs-situs yang bernilai budaya bagi masyarakat Desa Pattaneteang, hingga saat ini belum pernah ada penelitian arkeologis yang meniliti situs-situs tersebut. 
Berdasarkan durasi kegiatan dan sumebr daya yang digunakan, pemetaan dengan menggunakan drone (UAV) ini dilaksanakan dalam waktu singkat dan didukung dengan kegiatan FGD yang efektif, sehingga pendekatan DPM mempersingkat waktu, sumber daya manusia dan kapital dibandingkan dengan pendekatan konvensional yang kerap dilakukan dalam penentuan batas administrasi lanskap pedesaan di Indonesia.

\section{SIMPULAN}

Penilaian potensi jasa lanskap keanekaragaman hayati dan kandungan karbon tersimpan kawasan hutan Desa Pattaneteang yang dilakukan berdasarkan delapan kelompok penggunaan lahan menunjukkan bahwa hutan inti adalah kawasan yang memiliki nilai potensi terbesar yaitu 1836.56 . Hal ini dikarenakan kawasan hutan inti merupakan bagian dari Kawasan Hutan Lindung Gunung Bawakaraeng-Lompobattang yang kondisi hutannya masih sangat baik. Kualitas jasa lanskap keanekaragaman hayati dan karbon tersimpan di Desa Pattaneteang berada dalam tingkatan "sangat baik", memiliki peran ekonomi bernilai tinggi pada Hutan Desa Pemanfaatan.Total nilai scoring peran budaya Hutan Desa Pattaneteang yaitu 4 untuk kawasan Hutan Desa Sengketa dan Hutan Desa Pemanfataan, yang artinya bernilai budaya rendah dan nilai 5 untuk kawasan Hutan Desa Inti yang artinya bernilai budaya sedang. Secara keseluruhan pemetaan hasil jasa lanskap dapat digunakan sebagai alat pendukung dalam pengambilan keputusan bagi perencana dan pemuat kebijakan dengan mempertimbangkan faktor-faktor yang mendasari ekologi maupun sosial. Pemetaan jasa lanskap memberikan gambaran secara komprehensif tentang kondisi ekologi maupun permintaan dan kebutuhan masyarakat setempat secara efisien dan efektif dari aspek waktu, tenaga dan biaya.

\section{UCAPAN TERIMA KASIH}

Ucapan terima kasih disampaikan atas dukungan dari Kementerian Riset Teknologi dan Badan Riset Inovasi Nasional Republik Indonesia melalui skema Penelitian Tesis Magister (PTM) berjudul "Manajemen Lanskap Hutan Desa melalui Drone Participatory Mapping di Kabupaten Bantaeng Sulawesi Selatan" dengan kontrak nomor 1/E1/KP.PTNBH/2020.

\section{DAFTAR PUSTAKA}

[MEA] Millennium Ecosystem Assessment. 2005. Ecosystems and Human Well-Being. Volume ke-5. Washington DC (US): Island Press.

[MENHUT] Kementerian Kehutanan. 2010. Surat Keputusan Menteri Kehutanan No. 55/Manhut-II/2010 tentang Penetapan Kawasan Hutan sebagai Areal Kerja Hutan Desa pada Hutan Lindung Seluas 342 Hektar Terletak dalam Wilayah Administrasi Desa Labbo, Kecamatan Tompobulu, Kabupaten Bantaeng, Provinsi Sulawesi Selatan. Jakarta (ID): Kementerian Kehutanan.

Anneli JA, Mäkipää R, Ståhl G, Lehtonen A, Petersson H. 2007. Estimation of the biomass stock of trees in Sweden: comparison of biomass equations and age-dependent biomass expansion factors. Ann For Sci. 64: 219-228. doi: 10.1051/forest.

Baró F, Palomo I, Zulian G, Vizcaino P, Haase D, Gómez-Baggethun E. 2016. Mapping ecosystem service capacity, flow and demand for landscape and urban planning: A case study in the Barcelona metropolitan region. Land Use policy. 57: 405-417. doi: 10.1016/j.landusepol.2016.06.006.

Batari A, Jusuf Y, Sahide MAK. 2017. Analisis tingkat keaktifan pengelolaan Hutan Desa Labbo. J Hutan dan Masy. 9(1): 54. doi: 10.24259/jhm.v9i1.1837.

Bösch M, Elsasser P, Franz K, Lorenz M, Moning C, Olschewski R, Rödl A, Schneider H, Schröppel B, Weller P. 2018. Forest ecosystem services in rural areas of Germany: Insights from the national TEEB study. Ecosyst Serv. 31: 77-83. doi: 10.1016/j.ecoser.2018.03.014.

Brown G, Kyttä M. 2018. Key issues and priorities in participatory mapping: Toward integration or increased specialization?. Appl Geogr. 95: 1-8. doi: 10.1016/j.apgeog.2018.04.002. 
Byron N, Arnold M. 1999. What Futures for People of the Tropical Forests?. World Development. 27(5): 789805.

da Silva PG, Nunes CA, Ferreira LF, Braga RF, Beiroz W, Perillo LN, Solar RRC, de Siqueira Neves F. 2019. Patch and landscape effects on forest-dependent dung beetles are masked by matrix-tolerant dung beetles in a mountaintop rainforest archipelago. Sci Total Environ. 651: 1321-1331. doi: 10.1016/j.scitotenv.2018.09.195.

De Vreese R, Leys M, Fontaine CM, Dendoncker N. 2016. Social mapping of perceived ecosystem services supply-the role of social landscape metrics and social hotspots for integrated ecosystem services assessment, landscape planning and management. Ecol Indic. 66: 517-533. doi: 10.1016/j.ecolind.2016.01.048.

Delgado-Aguilar MJ, Hinojosa L, Schmitt CB. 2019. Combining remote sensing techniques and participatory mapping to understand the relations between forest degradation and ecosystems services in a tropical rainforest. Appl Geogr. 104: 65-74. doi: 10.1016/j.apgeog.2019.02.003.

Delgado-Aguilar MJ, Konold W, Schmitt CB. 2017. Community mapping of ecosystem services in tropical rainforest of Ecuador. Ecol Indic. 73: 460-471. doi: 10.1016/j.ecolind.2016.10.020.

Gil MV, Blanco D, Carballo MT, Calvo LF. 2011. Carbon stock estimates for forests in the Castilla y León region, Spain. A GIS based method for evaluating spatial distribution of residual biomass for bio-energy. Biomass and Bioenergy. 35(1): 243-252. doi: 10.1016/j.biombioe.2010.08.004.

Graham V, Nurhidayah L, Astuti R. 2020. Reducing emissions from tropical deforestation and forest degradation. Di dalam: Reference Module in Earth Systems and Environmental Sciences. Elsevier Inc. hlm 1-9.

Gurung MB, Bigsby H, Cullen R, Manandhar U. 2015. Estimation of carbon stock under different management regimes of tropical forest in the Terai Arc Landscape, Nepal. For Ecol Manage. 356: 144-152. doi: 10.1016/j.foreco.2015.07.024.

Hairiah K, Ekadinata A, Sari RR, Rahayu S. 2011. Pengukuran Cadangan karbon; Dari Tingkat Lahan ke Bentang Lahan. Edisi Kedua. Malang (ID): World Agroforestry Centre.

Hendrawan DCP, Harja D, Rahayu S, Lusiana B, Dewi S. 2015. Agroforestri Kompleks di Bantaeng, Sulawesi Selatan: Pentingnya Peran Petani sebagai Agen Penyangga Keanekaragaman Hayati Tumbuhan. Di dalam: Prosiding Seminar Nasional Agroforestry. hlm 351-356.

Kaswanto RL. 2017. Management of landscape services for improving community welfare in West Java, Indonesia. Di dalam: Hong SK, Nakagoshi N, editor. Landscape Ecology for Sustainable Society. Cham (CH): Springer. hlm 251-270. doi: 10.1007/978-3-319-74328-8_15.

Kaswanto RL, Filqisthi TA, Choliq MBS. 2016. Revitalisasi pekarangan lanskap pedesaan sebagai penyedia jasa lanskap untuk meningkatkan kesejahteraan masyarakat. Jurnal Lanskap Indonesia. 8(1): 50-60. doi: 10.29244/jli.2016.8.1.50-60.

Konsorsium HVCN. 2008. Panduan Identifikasi Kawasan Bernilai Konservasi Tinggi di Indonesia. Revisi HCV Toolkit Indonesia. Balikpapan (ID): Tropenbos International Indonesia Programme.

Manuri S, Putra CAS, Saputra AD. 2011. Tehnik Pendugaan Cadangan Karbon Hutan. Palembang (ID): Merang REDD Pilot Project, German International Cooperation-GIZ.

Marques M, Oliveira M, Borges JG. 2020. An approach to assess actors' preferences and social learning to enhance participatory forest management planning. Trees, Forest and People. 2: 1-14. doi: 10.1016/j.tfp.2020.100026.

Sularso GNM, Hermawan R, Prasetyo LB. 2011. Pendugaan perubahan cadangan karbon di Taman Nasional Meru Betiri. Semiloka Nasional: Implementasi RAN-GRK untuk bidang berbasis lahan;2011 Oct 4; Bogor, Indonesia.

Nurhaedah M, Hapsari E. 2014. Hutan Desa Kabupaten Bantaeng dan Manfaatnya bagi Masyarakat. Info Tek. eboni. 11(22): 27-36. 
Nowak DJ, Crane DE. 2002. Carbon storage and sequestration by urban trees in the USA. Environ Pollut. 116(3): 381-389. doi: 10.1016/S0269-7491(01)00214-7.

Pemerintah Desa Pattaneteang. 2019. Pattaneteang Desa Untuk Indonesia 2019. Ed ke-1. Volume ke-1. Rahim M, editor. Bantaeng (ID): Pemerintah Desa Pattaneteang.

Powell PA, Nanni AS, Názaro MG, Loto D, Torres R, Gasparri NI. 2018. Characterization of forest carbon stocks at the landscape scale in the Argentine Dry Chaco. For Ecol Manage. 424: 21-27. doi: 10.1016/j.foreco.2018.04.033.

Rahayu S, Lusiana B, Amaruzaman S. 2017. Keragaman Jenis Pohon dan Pemanfaatannya oleh Masyarakat di Kabupaten Buol, Indonesia. Bogor (ID): ICRAFT.

Rasmussen LV, Watkins C, Agrawal A. 2017. Forest contributions to livelihoods in changing agricultureforest landscapes. For Policy Econ. 84: 1-8. doi: 10.1016/j.forpol.2017.04.010.

Rohmah G. 2014. Ecological and psychological carrying capacity of tourism in themepark, case study: Taman Wisata Matahari Cisarua Bogor [tesis]. Bogor (ID): Institut Pertanian Bogor.

Saputra AY, Wiryani E. 2013. Keanekaragaman tumbuhan pada berbagai tata guna lahan di kawasan kars pegunungan kendeng Desa Sukolilo, Pati. J Biol. 2(1): 9-18.

Siarudin M, Winara A, Indrajaya Y, Badrunasar A, Rahayu S, Roshetko JM. 2017. Seri Agroforestri dan Kehutanan di Sulawesi: Keanekaragaman Hayati Jenis Pohon pada Hutan Rakyat Agroforestri di DAS Balangtieng, Sulawesi Selatan. Bogor (ID): ICRAFT.

Siraj M. 2019. Forest carbon stocks in woody plants of Chilimo-Gaji Forest, Ethiopia: Implications of managing forests for climate change mitigation. South African J Bot. 127: 213-219. doi: 10.1016/j.sajb.2019.09.003.

Sjaf S. 2019. Republik Merdesa. Cetakan 1. Al-Mustofa O, Gumelar AD, editor. Bogor (ID): IPB Press.

Supratman JY, Alif KSM. 2010. Pendekatan Kolaborasi dalam Pengelolaan Taman Nasional Bantimurung Bulusaraung: Strategi Menyatukan Kepentingan Ekologi dan Sosial Ekonomi Masyarakat. Opinion Brief No. ECICBFM II-2010.02. The Center for People and Forest. RECOFTC. Makassar.

Supratman S, Sahide M. 2010. Pembangunan Hutan Desa di Kabupaten Bantaeng: Konsep, Proses, dan Refleksi. Bogor (ID): RECOFTC, The Center for People and Forest.

Swastikaningrum H, Hariyanto S, Irawan B. 2012. Keanekaragaman jenis burung pada berbagai tipe pemanfaatan lahan di kawasan muara kali lamong perbatasan Surabaya-Gresik. J Biol Res. 17(2): 131138. doi: 10.23869/bphjbr.17.2.20122.

Termorshuizen JW, Opdam P. 2009. Landscape services as a bridge between landscape ecology and sustainable development. Landscape Ecology. 24: 1037-1052. doi: 10.1007/s10980-008-9314-8.

Wijaya C, Rahayu S, Prasetyo A, Dwiyanti E. 2017. Dinamika Perubahan Penggunaan/Tutupan Lahan serta Cadangan Karbon di Kabupaten Buol Indonesia. Bogor (ID): World Agroforestry Center.

Wood A, Tolera M, Snell M, O'Hara P, Hailu A. 2019. Community forest management (CFM) in south-west Ethiopia: Maintaining forests, biodiversity and carbon stocks to support wild coffee conservation. Glob Environ Chang. 59: 1-19. doi: 10.1016/j.gloenvcha.2019.101980.

Zaehringer JG, Schwilch G, Andriamihaja OR, Ramamonjisoa B, Messerli P. 2017. Remote sensing combined with social-ecological data: The importance of diverse land uses for ecosystem service provision in north-eastern Madagascar. Ecosyst Serv. 25: 140-152. doi: 10.1016/j.ecoser.2017.04.004.

Zhu T, Krott M, Chen H. 2014. Co-management implementation in forested national reserves: Contradicting cases from China. For Policy Econ. 38: 72-80. doi: 10.1016/j.forpol.2013.07.005. 